\title{
The Relation Between Teacher-Student Eye Contact and Teachers' Interpersonal Behavior During Group Work: a Multiple-Person Gaze-Tracking Case Study in Secondary Mathematics Education
}

\author{
Eeva Haataja ${ }^{1}$ (D) Visajaani Salonen ${ }^{1}$ (D) Anu Laine $^{1}$ (D) $\cdot$ Miika Toivanen $^{1}$ (D) \\ Markku S. Hannula ${ }^{1}$ (D)
}

Published online: 24 May 2020

(C) The Author(s) 2020

\begin{abstract}
Reciprocal eye contact is a significant part of human interaction, but its role in classroom interaction has remained unexplored, mostly due to methodological issues. A novel approach in educational science, multiple-person mobile gaze-tracking, allows us to gather data on these momentary processes of nonverbal interaction. The current mixedmethod case study investigates the role of teacher-student eye contact in interpersonal classroom interaction using this methodological approach from three mathematics lessons. We combined gaze-tracking data with classroom videos, which we analyzed with continuous coding of teachers' interpersonal behavior. Our results show that teacher communion and agency affect the frequency and durations of teachers and students' gazes at each other. Students tend to gaze their teachers more during high teacher communion and low agency, but qualitative and quantitative differences between the teachers and their classes emerged as well. To conclude, the formation of eye contacts is situational and affected by momentary interpersonal changes as well as the qualities of teacher-student interactions.
\end{abstract}

Keywords Continuous coding · Interpersonal theory $\cdot$ Mathematics education · Mobile gazetracking $\cdot$ Teacher-student interaction

\section{Introduction}

Recent research has shown the significance of micro-level interactional processes as building blocks of interpersonal relationships in education (Pennings et al. 2018). Teachers consider positive interaction with students as one of the most important sources of positive emotions

Eeva Haataja

eeva.haataja@helsinki.fi

Extended author information available on the last page of the article 
(Chen 2016) while experiences of unsuccessful teacher-student interactions correlate with a sense of decreased professional agency (Heikonen et al. 2017). Teachers' interaction skills are essential for effective classroom management, deserving to be focused on in teacher education and professional development (Arsenijevic et al. 2017).

Pennings with her colleagues have investigated how teacher-student relationships (macrolevel) in the classroom are built on momentary interactions (micro-level) (Pennings et al. 2014; 2018). This recent dimension of the interpersonal theory (Kiesler 1983) enlightens the adaptivity and reciprocity of teacher-student interaction (Pennings et al. 2018) but is still lacking details on how these micro-level mechanisms work and relate to the macro-level. For example, Pennings and her colleagues (2018) analyzed the micro-level interaction processes using a half-second time frame, but, on the other hand, they consider the teacher to be interacting with the class as a whole. Our study moves from the level of whole-class interaction to reciprocal communication between the teacher and individual students.

Teacher's gaze (i.e., what they look at) allows teachers to differentiate their interaction with students. According to teachers, eye contact with students (i.e., both gaze at each other) is an element of good teacher-student interaction (Korthagen et al. 2014). Teacher gaze is part of the nonverbal interaction that reflects teacher-student interpersonal relationships. Teachers who gaze at the students during listening to them are, according to students, preferred over teachers who gaze at them during teacher talk (McIntyre 2016).

The complexity and situationality of gaze and eye contact interactions highlight the importance of collecting data in authentic contexts (Tatler and Land 2015). Students' nonverbal messages affect teacher behavior and student learning (Mottet et al. 2016). While this nonverbal communication is reciprocal, it is important to study both teacher and student gazes simultaneously (Mottet et al. 2016). The gaze interaction becomes complex when multiple students require teacher attention. These aspects suggest that to study the role of eye contact in teaching, we must develop methods for multiple-person gaze-tracking in natural classroom interaction.

New mobile (i.e., wearable when moving around) gaze trackers provide us with a possibility to examine the momentary teacher-student interactions in natural environments (Haataja et al. 2019a; Haataja et al. 2019b; Pennings et al. 2018). While interviews (e.g., Korthagen et al. 2014) and questionnaires (e.g., McIntyre et al. 2017) have shown that eye contacts are important for both students and teachers, this aspect has not yet been integrated into the interpersonal theory. Moreover, neither self-reflections nor laboratory experiments can provide access to the processes of situational eye contact interaction in a classroom context. This study examines the reciprocal formation of teacher-student eye contacts through the eyes of eleven students and three teachers together with the teachers' interpersonal behaviors during mathematical problem-solving lessons. We examine the relationship between the propensity of teacher and student gazes at each other and the changes in teacher interpersonal behavior.

\section{Teachers' Interpersonal Behaviors}

According to the interpersonal theory, human interaction is conceptualized as a continuous cycle of initiatives and responses between people (Kiesler 1983). This cycle has been conceptualized with two dimensions: agency and communion (Gurtman 2009; Kiesler 1983). Earlier research examines this phenomenon using various concepts. Agency has been discussed as actions of authority (Mehrabian 1972), status (McIntyre 2016), dominance (Akechi et al. 2013), power (Brey and Shutts 2015), and control that convey a person's urge 
to be differentiated as an individual (Gurtman 2009; Wiggins 1991), whereas communion connotes nonverbal immediacy (Andersen et al. 1979; Mehrabian 1972), union, and affiliation that manifest a person's striving for belonging in a social entity (Gurtman 2009; Wiggins, 1991). Teachers' interpersonal behavior usually ranges within the field of positive communion and agency (Pennings et al. 2018). In a classroom situation, teacher interpersonal behavior is adaptive to the students' behavior (Pennings et al. 2018). Figure 1 shows this combination in teacher-student classroom interaction from the perspective of the teachers and the students. In Fig. 1, we use the sector labels by Pennings et al. (2018), which are adapted from teacher and student circles in Claessens et al. (2017). Due to the different roles for teacher and students in the classroom, the same communion and agency are related to somewhat different behaviors in student and teacher interpersonal circles. This is reflected in the different terms in the same position of the circle (e.g., imposing teacher vs. critical student).

In social interaction, people tend to respond to high agency with low agency and vice versa, while for communion, they tend to respond with similar communion (e.g., Kiesler 1996). Regardless of the interpersonal theory's origins in natural and unstructured interaction contexts (Kiesler 1996), it has been found to be applicable in teacher-student interaction as well (Pennings et al. 2018). There are some special tendencies, such as the teachers' directing role in the adaptation and refrainment from natural hostile responses to students' hostile behavior (Pennings et al. 2018). Teachers and students adapt the behaviors of communion and agency according to the perceived and anticipated behaviors of each other (Pennings et al. 2018). For example, a teacher's behavior reflecting high agency is found to increase communion among students and, vice versa, a teacher's high level of communion decreases students' agency (Pennings et al. 2018).

Students seek information from eye contacts with the teacher (Böckler et al. 2014). While recent research has found the gaze patterns to be directed by teachers' pedagogical approach and expertise (McIntyre and Foulsham 2018), the momentary changes of teacher-student interaction are rather situational (Pennings et al. 2014).

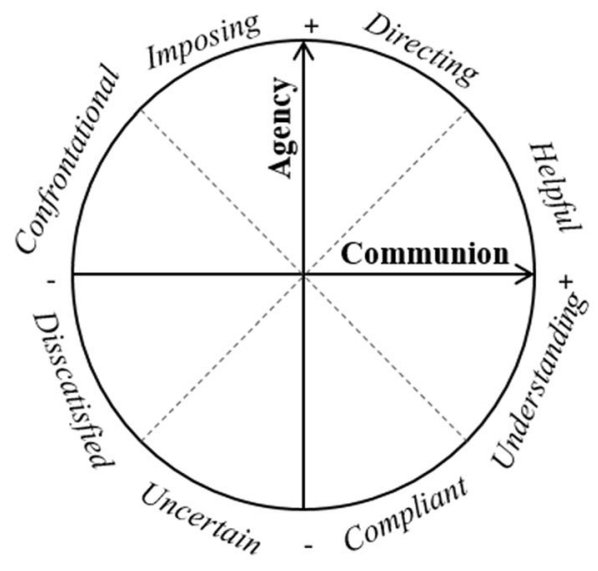

Interpersonal circle - teacher

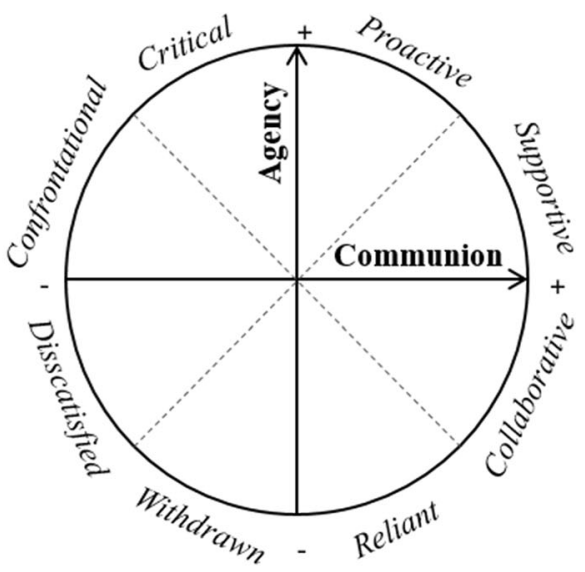

Interpersonal circle - student

Fig. 1 The interpersonal cycles for teacher and student interpersonal behavior (adapted from Pennings et al. 2018; see also Claessens et al. 2017). Student interpersonal cycle refers to student interaction with teacher 


\section{Communion in Teacher-Student Eye Contacts}

In social interaction, occurrence of eye contact transfers experiences of communion and warmth towards the other person (Mehrabian 1972). Through eye contact, the teacher communicates to students that attention is towards them and she teaches for them (Adams Jr. et al. 2013; Ellis 2000; McIntyre et al. 2017). Teachers' eye contacts, together with their open body positions, create a positive atmosphere that encourages students into participation and interaction (Roberts and Friedman 2013). Teachers' behaviors of nonverbal communion, such as eye contacts (Andersen et al. 1979; Mehrabian 1972), as well as students' perceptions of their teacher's interest in them, correlate positively with learning and engagement in mathematics (Ellis 2000; McCluskey et al. 2017). In our recent case study, the teacher directed visual attention at student faces during the problem-solving process while scaffolding affectivelearning goals (Haataja et al. 2019a).

\section{Agency in Teacher-Student Eye Contacts}

Looking someone directly in the eye tells about a person's social agency (Brey and Shutts 2015; Mehrabian 1972). People tend to respond to the direct gaze of a person with high agency with shorter fixations (Akechi et al. 2013). With direct gaze at student faces, the teacher can show students their role in the instruction and the meaningfulness of the learning contents (Böckler et al. 2014).

During teacher-centered instruction, the proportion of teachers' student-targeted gazes is similar during speaking (high agency) and listening (low agency) to students (McIntyre and Foulsham 2018). Students experience a close relationship with a teacher who gazes towards them while listening to them (McIntyre et al. 2017). Student questionnaires have shown that in situations of high teacher agency, students tend to relate a teacher's eye contact with communication of authority and dominance and expect the teacher to gaze at relevant targets in the environment rather than to seek for an eye contact (McIntyre 2016). However, momentary teacher-student eye contacts have remained uninvestigated from student perspective or during group work. This study examines how responsiveness to teacher agency and communion is evident in the gaze behavior of the students in the context of reciprocal teacher-student interaction.

\section{Research Questions}

The research on interpersonal theory and on teachers' visual attention has shown the rationale of exploring eye contacts as a part of teacher-student interaction in authentic classrooms. To explore the one-sided face-targeted gazes and dyadic eye contacts between teachers and students, our research questions were the following:

1. What kind of connection is there between the teachers' momentary interpersonal behavior and the occurrence and the durations of teacher gazes at their students?

2. How does the teachers' momentary interpersonal behavior relate with the occurrence and the durations of (a) student gazes at their teacher and (b) student-started eye contacts? 


\section{Methods}

To examine the formation of teacher-student eye contacts as a part of authentic classroom interaction, we collected data on three ninth-grade mathematics lessons between May 2017 and February 2018. The participating classes in three Finnish schools included 15-16-year-old students. All the teachers had taught the participating classes since the beginning of the seventh grade, that is, for more than 2 years. The research project has a review and an approval of the University of Helsinki Ethical Review Board in the Humanities and Social and Behavioral Sciences. With their principals' permission, the teachers, and all students present in data collection volunteered and filled written consent forms. The students' parents were informed on the data collection. To acknowledge their contribution, the subjects of the gaze-tracking received gift cards, and the classes received small donations.

\section{Participants}

Three teachers and their 47 students participated in the study. The first teacher was a 39-yearold with 14 years of teaching experience. In this research, we call her with pseudonym Joanne. Her class consisted of seven boys and twelve girls. During the collaboration phase, which is in the focus in this study, these students were seated in five groups of three to five students. The target students wearing gaze-tracking glasses formed a group of four girls in Joanne's class. Joanne's students appearing in the excerpts are called with letters A-D.

The second teacher, called with pseudonym Fred, was a 30-year-old with 3 years of experience in teaching. Fred's class had eleven boys and eight girls who worked in five groups of two to four students. In Fred's class, the target group consisted of four boys. Unfortunately, due to malfunction of one gaze-tracker, we were able to use the gaze data of only three students from this lesson. In the excerpt, Fred's students are referred to as numbers 1-3.

The third teacher is called Lily in this report. She was a 56-year-old and had 31 years of teaching experience. On the day of the data collection, Lily had six boys and three girls on her lesson, of which three boys and one girl formed the target group (students $\mathrm{X}$ and $\mathrm{Y}$ in the excerpt). Lily's students sat in groups of four, three, and two.

\section{Devices}

With all classes, three stationary video cameras in the classroom recorded the actions and verbal interactions during the lesson. The eye movements of the target students and the teachers were recorded with mobile gaze-tracking glasses (Toivanen et al. 2017), which consisted of two eye cameras, a scene camera, and simple electronics, attached to 3D-printed eyeglasses-like frames. The accuracy of the device was 1.5 degrees of visual angle. We used software that computed the gaze target coordinates on the scene video.

\section{Research Setting}

The research group visited two mathematics lessons with all classes. The purpose of the first lesson was to help students to become accustomed to the equipment and to calibrate the glasses. The actual data collection and the collaborative problem solving took place during the second lesson. In this study, we used the data from the collaborative problem-solving phases that lasted $16-18 \mathrm{~min}$ in all classes. The goal of the problem task was to find the optimal way 
to connect a cable between four imaginary cities located at the vertices of a square. To solve the problem, students were allowed to use paper, pencils, rulers, and calculators. In Lily's class, the students used laptop computers with Geogebra software as well. A detailed description of the problem task is published in Authors Haataja et al. (2019a).

The researchers instructed the teachers to support the students in the problem-solving process through encouraging and posing questions but not giving hints towards the right solution. During the session, all teachers roamed in the classrooms and offered scaffolding to one group at a time. Additionally, Joanne and Lily instructed their students to wander in the class to see the solutions of other collaborating groups.

\section{Analysis}

We used a mixed methods approach in analyzing the data from classroom videos and gaze recordings. For analyzing gaze and classroom video data, we used continuous coding. Continuous coding provides us with information on the dynamics of micro-level processes of teacher-student interaction (Pennings et al. 2018), allowing us to make predictions and explanations of their behavior (Schmitz 2006). Table 1 portrays the variables and methods of analyses that are presented in this section.

The first and second author coded the teachers' interpersonal behavior according to the interpersonal theory, using Sadler's computer-joystick method (e.g., Lizdek et al. 2012; Sadler et al. 2009). According to this established method, using a joystick and a special software, we watched the classroom videos, simultaneously coding the teachers' interactions using Cartesian coordinates, with communion on the $x$-axis, ranging from hostility $(-1000)$ to friendliness (1000), and agency on the $y$-axis, ranging from submission (-1000) to dominance (1000) (see Sadler et al. 2009; Wiggins 1991).

The computer-joystick method has been validated by several studies in the fields of psychology (Thomas et al. 2014) and education (Pennings et al. 2018). In this study, we confirmed the validity of the coding by conducting it twice by two researchers. After the first coding, the researchers discussed the emerging issues and divergences, searching previous research for answers to them. After this, the coding was conducted again. After the second coding, we calculated the inter-rater reliability with interclass correlation on teacher communion ( 0.641 with a $95 \%$ confidence interval from 0.624 to $0.658, F(1,6620)=26.18, p<.001)$ and on teacher

Table 1 The variables used in this research

\begin{tabular}{|c|c|c|c|c|}
\hline Variable & Data source & Coding method & Analysis method & RQ \\
\hline $\begin{array}{l}\text { Teacher } \\
\text { communion } \\
\text { and agency } \\
2\end{array}$ & Classroom video & Computer-joystick method & $\begin{array}{l}\text { ANOVA, Pearson } \\
\text { correlations, qualitative } \\
\text { descriptions }\end{array}$ & 1 , \\
\hline Gaze targets & Gaze recordings & ELAN annotation & $\begin{array}{l}\text { ANOVA, qualitative } \\
\text { descriptions }\end{array}$ & 1 , \\
\hline 2 & & & & \\
\hline $\begin{array}{l}\text { Gaze durations } \\
\quad 2\end{array}$ & Gaze recordings & ELAN annotation & Pearson correlations & 1 , \\
\hline Observations & classroom video & Researcher notes & Qualitative descriptions & 2 \\
\hline Excerpts & $\begin{array}{l}\text { Classroom video, gaze } \\
\text { recordings and } \\
\text { transcript }\end{array}$ & $\begin{array}{l}\text { Selection of typical moments by } \\
\text { mean levels of communion and } \\
\text { agency }\end{array}$ & Qualitative descriptions & 2 \\
\hline
\end{tabular}


agency $(0.913$ with a $95 \%$ confidence interval from 0.909 to $0.917, F(1,6620)=21.22, p<.001)$, which is in line with previous research with the same method of analysis (Pennings et al. 2018). In the analysis, we used the average of the scores of the two researchers on the second round.

The first author coded the gazes with ELAN software (Version 5.2, 2018; Lausberg and Sloetjes 2009) with a dwell as a coding unit. Dwell is a single gaze on a specific target (e.g., face) (Holmqvist et al. 2011). Each dwell was coded according to its target and duration. After the coding, we first identified one-sided face-targeted dwells (teacher gazes at student face but student does not look back, student gazes at teacher face but teacher does not look back) and dyadic eye contacts. Secondly, we divided dyadic eye contacts into two categories according to the initiator (teacher-started, student-started). In Lily's lesson, some technical issues with a student laptop computer stole her time, which may explain the high proportion of student gazes towards her compared with the dyadic eye contacts.

We synchronized the joystick and ELAN gaze codings to chart the relations between teachers' interpersonal behavior and the gaze targets and durations. We combined the gaze and joystick coding points by dividing the gazes between half-second intervals. Each gaze shorter than $0.5 \mathrm{~s}$ was coded as a separate unit with a connection to the level of communion and agency at the time. The gazes longer than $0.5 \mathrm{~s}$ were split into fragments of half a second.

We compared teacher communion and agency with gaze targets using two-way ANOVA within subject, having the teacher communion and agency as dependent variables and the occurrence of gaze targets as independent variables. Moreover, we compared dwell durations using Pearson correlation. For the reliability of the correlations, we used logarithm transformed values of the gaze durations, removing the outliers (teacher not in interaction with the students: Agency $=-1000$ ) from the consequent analysis.

These analyses were complemented with transcripts of the classroom videos and observations by the first two authors who are qualified teachers with years of experience. We selected excerpts from the transcribed classroom video by searching for moments when teacher communion and agency were within one standard deviation of the average on the specific gaze type. From these moments, we selected those that included several gazes of the searched type to represent a typical case of the specific gaze behavior. We describe these moments qualitatively, interpreting them in the context of the whole lesson. In the excerpts of the verbal interaction, the moments of face-targeted gazes between the teachers and students are underlined (teacher gaze at student face, teacher-started dyadic eye contact, student-started dyadic eye contact, and student gaze at teacher face).

The researchers observing the classroom videos agreed that there were some differences in the teacher-student interaction between the classes. In all classes, only some students managed to solve the problem. This study examines the phase when none of the students knew the optimal solution. Joanne's target students were eventually able to find the optimal solution, while Fred or Lily's target students were not. Some pedagogical differences occurred between the teachers as well. Joanne gave some whole-class instructions and asked students to walk around and change seats, whereas Fred and Lily used the collaborative phase almost completely for group-level scaffolding.

\section{Results}

We first present a descriptive overview of the interpersonal behaviors and face-targeted gazes during the lessons. Second, we examine the durations of teacher gazes at all the students in the 
classroom in relation to the teachers' interpersonal behavior. Finally, the results on student gazes towards teachers are explored. As we found the quantitative results of the student gaze data interesting, we complement this analysis with qualitative reflections.

\section{Overview on the Relation Between Teachers' Interpersonal Behaviors and Their Gazes}

This overview serves as background information for the following sections answering the research questions. Figure 2 shows the interpersonal behaviors of the teachers during the collaborative phases of mathematical problem solving.

The teachers' interpersonal behavior varied mainly within positive levels of communion and agency. During the collaborative problem-solving phase of the lesson, Joanne scored means of $293.9(S D=210.5)$ in communion and $253.1(S D=468.2)$ in agency. Fred's mean scores were $241.5(S D=228.2)$ in communion and $295.8(S D=343.7)$ in agency, and Lily's $120.2(S D=178.7)$ in communion and $-10.6(S D=635.1)$ in agency.

Table 2 shows the distributions of the gazes between the teachers and gaze categories of four types of teacher-student eye contacts: teacher gaze at student face, teacher-started dyadic eye contact, student-started dyadic eye contact, and student gaze at teacher's face. Table 3 presents the mean durations of the gazes according to the exhaustive gaze coding.

One-sided face-targeted gazes were more frequent than dyadic eye contacts. Teacher gazes at student faces was the most frequent category $(n=677)$, followed by student gazes at teacher faces $(n=512)$. Student-started dyadic eye contacts were more common $(n=298)$ than teacher-started dyadic eye contacts $(n=175)$.

Table 4 shows the mean scores of teacher communion and agency during the gaze categories.

Overall, the teacher communion was strong during the student gazes at teacher faces and student-started eye contacts. Teacher agency, however, was the highest during teacher-started eye contacts and teacher gazes at student faces.

\section{Teacher Communion and Agency During Teacher Gazes at Student Face and Teacher-Started Eye Contacts}

As a result of research question 1, we found teacher gazes at student faces and teacher-started dyadic eye contacts occurring often during low teacher communion and high agency. The correlations between the gaze durations and levels of teacher communion and agency are presented in Table 5 and examined in detail in the following sections.
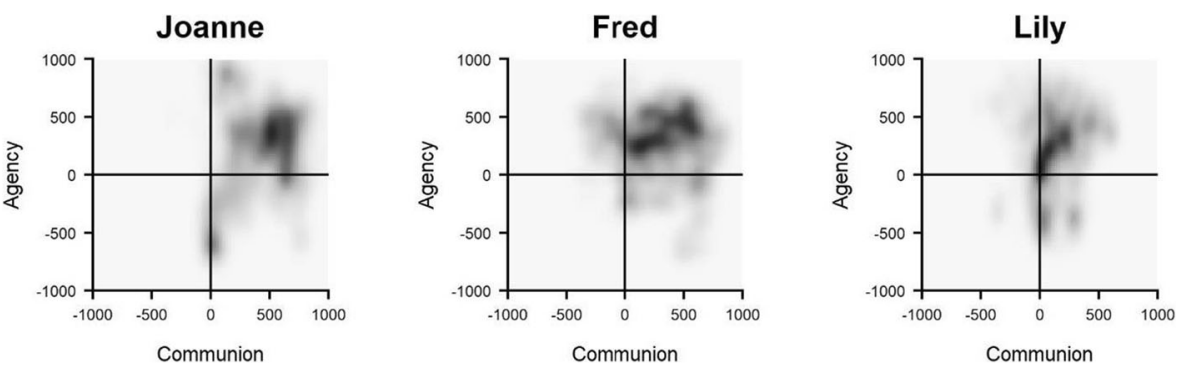

Fig. 2 Density heatmaps of the interpersonal behavior of three teachers 
Table 2 Percentages of dwells in different gaze categories

\begin{tabular}{|c|c|c|c|c|c|}
\hline & $\begin{array}{l}\text { (1) Teacher gaze at } \\
\text { student face }\end{array}$ & $\begin{array}{l}\text { (2) Teacher-started } \\
\text { eye contact }\end{array}$ & $\begin{array}{l}\text { (3) Student-started } \\
\text { eye contact }\end{array}$ & $\begin{array}{l}\text { (4) Student gaze at } \\
\text { teacher face }\end{array}$ & Total \\
\hline Joanne & $39 \%, n=189$ & $11 \%, n=51$ & $29 \%, n=137$ & $21 \%, n=103$ & $n=480$ \\
\hline Fred & $44 \%, n=305$ & $12 \%, n=86$ & $18 \%, n=125$ & $26 \%, n=181$ & $n=697$ \\
\hline Lily & $38 \%, n=183$ & $8 \%, n=38$ & $7 \%, n=36$ & $47 \%, n=228$ & $n=485$ \\
\hline
\end{tabular}

There was a positive correlation between gaze durations of teacher gazes at student faces and teacher communion with longer durations corresponding with higher communion $(r(670)$ $=.079, p=.041)$. This correlation was led by Joanne's data $(r(185)=.325, p<.001)$. In Fred's data, the durations of teacher gazes correlated positively with his level of agency $(r(303)=$ $.136, p=.017)$.

Teacher-started dyadic eye contacts were the rarest gaze type. Even though these gazes were frequent, they were shorter during high teacher agency. The correlation between the durations of teacher-started eye contacts and teacher agency was negative $(r(171)=-.224, p=$ $.003)$. This result was also led by Joanne's data, where the correlation between teacher agency and the durations of teacher-started eye contacts was quite strong $(r(49)=-.671, p<.001)$. Moreover, there was a significant positive correlation between Joanne's communion and the durations of the dyadic eye contacts she started $(r(49)=.586, p<.001)$.

\section{Teacher Communion and Agency During Student Gazes at Teacher Face}

To address research question $2 \mathrm{a}$, student gazes are first explored in relation to teacher communion and secondly to teacher agency. In the comparison of all face-targeted gazes, the students gazed at their teachers' faces more often and with longer gazes during high teacher communion. The correlation between student gazes at teacher faces and teacher communion was positive, with longer gazes corresponding with higher communion $(r(502)=.292, p<$ $.001)$. ANOVA on teacher communion as a dependent variable and the occurrence of gaze targets as independent variable yielded a significant effect of eye contact on teacher communion $\left(F(3,1658)=16.8, p<.001, \eta^{2}=0.029\right)$. The Bonferroni adjusted post hoc test revealed that student gazes at teacher faces had a significantly higher mean of teacher communion than teacher gazes at student faces $(p<.001)$, teacher-started eye contacts $(p<.001)$, and studentstarted eye contacts $(p=.005)$. The following comparison between the teachers provides us with details on this result (see Table 2).

With Joanne $\left(F(3,476)=11.3, p<.001, \eta^{2}=0.067\right)$ and Fred $(F(3,693)=34.5, p<.001$, $\eta^{2}=0.130$ ), this difference was significant compared with teacher gazes on student faces (both

Table 3 The mean durations of the dwells in different gaze categories in milliseconds

\begin{tabular}{|c|c|c|c|c|c|c|c|c|}
\hline & \multicolumn{2}{|c|}{$\begin{array}{l}\text { (1) Teacher gaze at } \\
\text { student face }\end{array}$} & \multicolumn{2}{|c|}{$\begin{array}{l}\text { (2) Teacher-started eye } \\
\text { contact }\end{array}$} & \multicolumn{2}{|c|}{$\begin{array}{l}\text { (3) Student-started eye } \\
\text { contact }\end{array}$} & \multicolumn{2}{|c|}{$\begin{array}{l}\text { (4) Student gaze at } \\
\text { teacher face }\end{array}$} \\
\hline & $M$ & $S D$ & $M$ & $S D$ & $M$ & $S D$ & $M$ & $S D$ \\
\hline Joanne & 448.1 & 515.4 & 1522.6 & 1017.8 & 1262.9 & 1376.3 & 1075.7 & 972.5 \\
\hline Fred & 506.1 & 387.8 & 2004.7 & 1423.7 & 1191.7 & 1142.7 & 1614.1 & 1401.4 \\
\hline Lily & 508.3 & 457.7 & 2094.4 & 2116.9 & 521.1 & 324.8 & 646.6 & 519.3 \\
\hline
\end{tabular}


Table 4 The mean scores and standard deviations of teacher communion and agency $(-1000,+1000)$ during moments of four types of teacher-student eye contacts. The shades of cells represent the order of the means on each row (the darker the cell, the higher the mean)

\begin{tabular}{|c|c|c|c|c|c|c|c|c|c|}
\hline & & \multicolumn{2}{|c|}{1 Teacher gaze } & \multicolumn{2}{|c|}{$\begin{array}{l}2 \text { Teacher-started } \\
\text { eye contact }\end{array}$} & \multicolumn{2}{|c|}{$\begin{array}{l}3 \text { Student-started } \\
\text { eye contact }\end{array}$} & \multicolumn{2}{|c|}{4 Student gaze } \\
\hline & & $M$ & $S D$ & $M$ & $S D$ & $M$ & $S D$ & $M$ & $S D$ \\
\hline \multirow[t]{4}{*}{ Communion } & Joanne & 235.3 & 188.7 & 272.2 & 211.3 & 290.8 & 189.0 & 381.1 & 247.2 \\
\hline & Fred & 207.4 & 213.4 & 181.7 & 236.5 & 177.1 & 242.6 & 387.4 & 207.7 \\
\hline & Lily & 129.1 & 228.9 & 112.1 & 157.4 & 170.0 & 172.2 & 152.1 & 159.0 \\
\hline & All & 194.0 & 214.9 & 193.9 & 221.2 & 228.1 & 218.3 & 281.4 & 228.2 \\
\hline \multirow[t]{4}{*}{ Agency } & Joanne & 544.8 & 338.9 & 572.1 & 253.7 & 447.3 & 405.1 & 597.9 & 221.5 \\
\hline & Fred & 405.5 & 173.9 & 408.0 & 155.0 & 437.4 & 150.4 & 390.6 & 205.0 \\
\hline & Lily & 492.3 & 329.7 & 459.8 & 162.6 & 394.4 & 204.5 & 268.1 & 407.4 \\
\hline & All & 467.9 & 279.9 & 476.1 & 202.5 & 436.5 & 299.2 & 377.8 & 336.9 \\
\hline
\end{tabular}

$p<.001$ ), teacher-started eye contacts (Joanne $p=.012$; Fred $p<.001$ ), and student-started eye contacts (Joanne $p=.005$; Fred $p<.001$ ). With Lily, ANOVA did not yield a significant effect of eye contact on teacher communion $(F(3,481)=1.07, p=.360)$, but this gaze category had the second-highest mean of teacher communion.

The correlation between the durations of the student gazes at Joanne's face and teacher communion was significant and positive $(r(101)=.240, p=.015)$. The correlation of the durations of student gazes at Fred's face and his behaviors of communion was positive $(r(179)$ $=.201, p=.007)$. In Lily's data, the correlation was not significant.

On teacher agency, the teachers differed more from each other. The analysis of variance yielded statistically significant effect of teacher-student eye contact on teacher agency $(F(3$, $\left.1658)=9.88, p<.001, \eta^{2}=0.018\right)$, between the gaze categories. The mean of teacher agency was significantly lower during student gazes at teacher faces than during teacher gazes at student faces $(p<.001)$, teacher-started eye contacts $(p=.004)$, and student-started eye

Table 5 Correlations of the durations of the gaze types and teacher agency and communion

\begin{tabular}{llllll}
\hline & & $\begin{array}{l}\text { Teacher gazes at } \\
\text { student faces } \\
\text { Duration }\end{array}$ & $\begin{array}{l}\text { Teacher-started eye } \\
\text { contacts } \\
\text { Duration }\end{array}$ & $\begin{array}{l}\text { Student-started eye } \\
\text { contacts } \\
\text { Duration }\end{array}$ & $\begin{array}{l}\text { Student gazes at } \\
\text { teacher faces } \\
\text { Duration }\end{array}$ \\
\hline \multirow{2}{*}{ Joanne } & Communion & $.325^{* *}$ & $.586^{* *}$ & $.218^{*}$ & $.240^{*}$ \\
Fred & Agency & .004 & $-.671^{* *}$ & $-.352^{* *}$ & $.344^{* *}$ \\
& Communion & .009 & -.121 & $-.267^{* *}$ & $.201^{* *}$ \\
\multirow{2}{*}{ Lily } & Agency & $.136^{*}$ & -.009 & $.178^{*}$ & .037 \\
& Communion & .016 & .095 & .006 & .121 \\
& Agency & -.009 & .161 & -.193 & .098 \\
& Communion & $.079 *$ & .114 & -.021 & $.292^{* *}$ \\
\hline
\end{tabular}

$* p<.05$

$* * p<.01$ 
contacts $(p=.038)$. However, the correlation of the duration of student gazes and teacher agency was slightly positive $(r(502)=.142, p=.001)$.

Fred's and Lily's results were aligned with this result. When Fred and Lily listened to their students or concentrated on their solutions, their students often looked at them. ANOVA with Fred's gaze data did not yield significant effect of eye contact on teacher agency $(F(3,693)=1.76, p=.153)$, but the mean agency was the lowest in this gaze category. With Lily, however, the effect was significant $(F(3,481)=14.43, p<.001$, $\left.\eta^{2}=0.83\right)$. In Lily's class, student gazes at teacher face occurred during the lowest teacher agency and differed from teacher gazes at student faces $(p<.001)$ and teacherstarted eye contacts $(p=.028)$.

The following excerpt from Lily's lesson (1484-1499 s, $M_{\mathrm{c}}=150.0, S D_{\mathrm{c}}=113.7, M_{\mathrm{a}}=$ $\left.265.5, S D_{\mathrm{a}}=124.9\right)$ presents an example of low teacher agency with several student gazes at Lily's face. In the beginning, student X wanted to show his solution to Lily. He led Lily to his seat that was already occupied by another student.

Lily: Okay, where is yours [solution]? Then student Y, please go to your own seat

Student X: Does not that [solution] look good? It is sweet and short, you know.

Lily: Short and sweet?

Student Y: Teacher, how about this one I made? [Points at a solution on the paper.]

Student X: Teacher did you see?

Lily [to student Y]: Okay, well draw that there [on the computer].

This moment started with Lily's understanding behavior with student X, while immediately shifting to directing behavior with student $\mathrm{Y}$. After letting student $\mathrm{X}$ capture her attention and lead her, she became enthusiastic, giving clear instructions as she saw a promising solution on student Y's paper. During this episode, we see the two students moving to collaborative behavior, while, at the same time, Lily's communion and agency increased as she moved to directing/helpful behavior.

With Joanne, the effect of eye contact on teacher agency was opposite $(F(3,476)=$ $\left.4.70, p=.003, \eta^{2}=0.029\right)$. Joanne's agency was significantly higher during the student gazes at teacher face than during the student-started eye contacts $(p=.003)$. High communion and agency were characteristic for Joanne and directed students' attention towards her. For example, while Joanne was instructing student A who had arrived late $\left(1258-1268 \mathrm{~s}, M_{\mathrm{c}}=329.0, S D_{\mathrm{c}}=72.2, M_{\mathrm{a}}=652, S D_{\mathrm{a}}=61.1\right)$, she captured the attention of target students student B and student C. Joanne looked at student A's face, while student A looked at the written instructions on the blackboard. A teacher-started eye contact occurred between the teacher and student A when the teacher confirmed student A's understanding of the task.

Joanne: Try to find the most optimal solution and [then] draw them on the board but now you can join a [group]...

Student A: They need to be in linked with each other

Joanne: Yes.

In this moment, Joanne's interpersonal behavior was directing. She instructed the late-arrived student to help her into the problem-solving process and peer collaboration. It is notable that student $\mathrm{C}$ and student $\mathrm{D}$ gazed at their teacher - reflecting a reliant behavior - even though she was not interacting with them nor was the information new to them. Thus, we suggest that the teacher's directing role was relevant in capturing their attention. 


\section{Teacher Communion and Agency During Student-Started Eye Contacts}

Student-started dyadic eye contacts were the category of the second-highest teacher communion and the lowest teacher agency (research question 2b). The durations of student-started dyadic eye contacts correlated positively with Joanne's $(r(129)=.218, p=.012)$ and negatively with Fred's $(r(123)=-.267, p=.003)$ levels of communion. In general, teacher agency and the durations of student-started eye contacts had a negative correlation, with longer gaze durations corresponding with lower teacher agency $(r(292)=-.147, p=.012)$.

In this gaze category, Fred's results differed from the others. In his lesson, the studentstarted eye contacts were frequent during low teacher communion. Additionally, the correlation between Fred's agency and the durations of the teacher-started eye contacts was positive $(r(123)=.178, p=.047)$. We interpreted this as an implementation of the reciprocal nature of scaffolding interaction. In addition to the teacher, the students were active initiators during scaffolding, but their initiatives were not mathematically productive and sometimes they even conflicted with the objectives of the lesson.

This exemplary moment of low teacher communion and high agency is from Fred's lesson $\left(455-465 \mathrm{~s}, M_{\mathrm{c}}=-27.4, S D_{\mathrm{c}}=177.9, M_{\mathrm{a}}=452.2, S D_{\mathrm{a}}=18.5\right)$. His behaviors of communion decreased to the negative values during this interaction. Fred was scaffolding the target group to help them start working on the task, but the students started misbehaving. In the beginning of the moment, Fred focused on student 2's paper to interpret his thinking process but was soon distracted. The student-started eye contact occurred at the end of the excerpt.

Fred: [Supportive tone] Hey, you already have two different [solutions].

Student 1: That [solution] is mine.

Student 2: That is mine!

Student 1: That is mine!

Fred: [Dissatisfied tone] Hey! Now you first should have thought of this alone.

Student 3: But can it go to a city via another city?

Fred: $\underline{\text { Yes. }}$

Student 4: Okay, then it must be this.

In this episode, Fred entered with an understanding behavior. However, the students' behavior was confrontational, to which Fred's initial reaction was dissatisfied, and thereafter his interpersonal behavior varied between imposing and directing. The dyadic eye contacts occurred at the end of the episode, when the teacher increased his agency in the interaction. This led to an immediate change in the behavior of student 3 , who disengaged from interaction with student 1 and student 2, changing his behavior to collaborative by posing a relevant question about the task. Also, student 4 behavior was collaborative.

In Lily's and Joanne's data, the students started dyadic eye contacts with the teachers often when they were active, and the teacher agency was low. An example of high communion and low agency from Joanne's data $\left(802-812 \mathrm{~s}, M_{\mathrm{c}}=388.2, S D_{\mathrm{c}}=94.2, M_{\mathrm{a}}=394.1, S D_{\mathrm{a}}=50.8\right)$ shows student D reflecting her thinking aloud. Joanne aimed at helping the students to compare their solutions and to choose the best one. She stood next to the group, leaning towards the students and speaking with a friendly and soft voice.

Joanne: Which result did you come to with those two [solutions]?

Student B: Maybe this one... 
Joanne: Okay.

Student C: I also think that maybe this one...

Student D: So, you cannot move the points?

Joanne: Yes, those four cities you are not allowed to move.

Student D: Yes...

In this moment, Joanne's interpersonal behaviors varied between helping and directing while the students responded with collaborative and reliant behavior. As she confirmed student D's idea, the friendly and calm tone in her voice conveyed supportiveness. The response to the student's eye contact initiative may have been one way of conveying a helping attitude to the students.

\section{Discussion}

This case study examined eye contacts as a micro-level implication of nonverbal interaction in the classroom and its relation to the interpersonal behaviors of three teachers. We found that teacher gazes at students occurred during lower communion and higher agency than student gazes at teachers, i.e., when the teacher was more directive than helpful. With regard to student-started eye contacts, we found that students' gazes were longer in duration, when teacher agency was lower. Moreover, our qualitative analysis allowed us to see that both teachers and students can use gaze to take initiative in their interactions with each other, using eye contact to create moments of more personal dyadic interaction within the overall classroom interaction. Despite the relatively similar interpersonal styles of the teachers, the personal differences were visible in the gaze behavior between the teachers and the students.

Regardless of the content of teacher-student interactions, high teacher communion evoked more student gazes at them, although the results did not reach statistical significance for Lily. Such gazes could relate to student collaborative behavior when the teacher interaction is helpful. This might be beneficial for the classroom interaction, as teacher gaze is an important factor influencing the quality of teacher-student interaction, thereby affecting students' learning (Bolkan et al. 2017; Mottet et al. 2008), teachers' well-being (McCluskey et al. 2017), and teachers' understanding of their professional adequacy and agency (Heikonen et al. 2017).

The students were able to express their situational social agency with a direct gaze (Brey and Shutts 2015). For example, Joanne responded to students' eye contact initiatives while also giving them space to take agency in the interaction. Likewise, Fred's students made gaze initiatives during low teacher agency but in these moments the student gaze often remained one-sided. Occasionally, students challenged his pedagogy both verbally and with gaze direction by starting dyadic eye contacts during Fred's low communion and high agency.

This study shows that the interpersonal adaptation in the classroom (Pennings et al. 2018) is visible on the level of gaze behavior. Students who wish to behave compliantly may show obedience through gaze direction or aversion, whereas students who challenge their teachers do it by direct gazes at their faces. Paying attention to the students' gaze direction or aversion during the instruction interactions could offer valuable information on their momentary interpretations of and intentions in the situation. In the future, this could be researched further and in other interactional contexts, such as during whole-class or personal instructions as well.

Reflecting the difference between teacher authority (macro-level) and agency (micro-level) could enhance teachers' ability to create a beneficial interactional climate in the classroom. The 
students' experiences of teacher's benevolence, which can be enhanced with efficient nonverbal interaction (Mehrabian 1972; Zeki 2009), seem to be built on momentary perceptions. If the teacher is agentic in the class, the students' gaze behaviors are more reactive to the teachers' actions.

\section{Methodological Considerations and Limitations}

Studies with large numbers of participants have found general patterns in teacher gaze behavior (e.g., McIntyre 2016) and teacher-student interpersonal adaptation (Pennings et al. 2018). In this case study, we found patterns in the relation between teacher interpersonal behavior and students' gaze behavior as well as qualitative interpretations of them. Our participant classes differed from each other with respect to teacher experience and observed student behavior. However, the content and the learning method of the lessons (problem solving), the grade of the classes, and the cultural context were standardized. Thus, the factor that cannot be standardized, the people, modified the interaction during the lessons and, therefore, our results. This micro-level study with multiple-person gaze-tracking in authentic classrooms shows significance in considering the tiniest differences in classroom interactions, such as the initiative part of a dyadic eye contact.

Despite the high accuracy of the gaze-tracking devises used, we cannot be sure that all the face-directed gazes were targeted at the eyes of the other person. We, however, interpreted that mutual gazing at each other's faces is essentially the same thing as an eye contact and, therefore, chose to call them eye contacts for the clarity of the report. The effect size of the statistical results was relatively low throughout the research. This is understandable, as human interactions are extremely complex phenomena, being impossible to explain comprehensively as a relation of four variables (communion, agency, gaze type, and gaze duration). Our results are not necessarily generalizable to other contexts, even if they offer novel information on the patterns of interactive gaze behavior during collaborative problem-solving lessons. Future studies with larger data sets, in various contexts, and by adding the student-student gazes into reflection would provide us with more insight into the role of gaze behavior in interpersonal interaction.

\section{Conclusion}

This case study explored the uncharted phenomenon of teacher-student eye contacts in relation to teachers' interpersonal behavior. During small-group scaffolding, the students were found to seek for eye contact with the teachers when the teachers conveyed communion. The teachers often used face-targeted gazes during high agency. For teachers, gaze allowed a way of differentiating interaction between students. Such individualization of micro-level interactions should be included in the further developments of interpersonal theory.

Taking interaction skills into the locus of teacher education and professional development could benefit the teachers' effectiveness (Allen et al. 2013) and classroom management (Arsenijevic et al. 2017). According to our study, the nonverbal teacher-student eye contact interaction is in relation to the teachers' other methods of conveying communion and agency in the classroom. Through behaviors of communion, the teachers can capture students' attention. With friendly eye contacts, the teachers can convey communion and give the agency 
to the engaged students. Especially, simultaneous high communion and modest agency is teacher behavior that encourages students' reciprocal eye contact interaction.

Combined with verbal reflection on the situation, eye contacts have a role in fruitful teacher-student interaction. The relation between students' gaze initiatives or aversion and the experiences of teacher-student relationship could serve as an interesting topic for future research. Both students' eye contact initiatives and gaze aversion can provide important information to the teacher. Acknowledging these nonverbal messages could be beneficial in constructing a fruitful teacher-student relationship.

Acknowledgments This research is a part of the MathTrack project that is funded by the Academy of Finland (grant 297856). We thank our participant teachers and students, and Mrs. Jessica Salminen-Saari, Dr. Enrique Garcia Moreno-Esteva, and Mr. Tran Phuoc for their contribution in the data collection and coding. We thank Dr. Laurinda Brown for her help with improving the language of the article.

Funding Information Open access funding provided by University of Helsinki. This research was funded by the Academy of Finland grant no. 297856.

\section{Compliance with Ethical Standards}

The research project has a review and an approval of the University of Helsinki Ethical Review Board in the Humanities and Social and Behavioral Sciences. With their principals' permission, the teachers, and all students present in data collection volunteered and filled written consent forms. The students' parents were informed on the data collection.

Conflict of Interest The authors declare they have no conflict of interest.

Open Access This article is licensed under a Creative Commons Attribution 4.0 International License, which permits use, sharing, adaptation, distribution and reproduction in any medium or format, as long as you give appropriate credit to the original author(s) and the source, provide a link to the Creative Commons licence, and indicate if changes were made. The images or other third party material in this article are included in the article's Creative Commons licence, unless indicated otherwise in a credit line to the material. If material is not included in the article's Creative Commons licence and your intended use is not permitted by statutory regulation or exceeds the permitted use, you will need to obtain permission directly from the copyright holder. To view a copy of this licence, visit http://creativecommons.org/licenses/by/4.0/.

\section{References}

Adams Jr., R. B., Nelson, A. J., \& Purring, K. (2013). Eye behavior. In J. A. Hall \& M. L. Knapp (Eds.), Nonverbal communication (pp. 229-262). New York: de Gryuter Berlin.

Akechi, H., Senju, A., Uibo, H., Kikuchi, Y., Hasegawa, T., \& Hietanen, J. K. (2013). Attention to eye contact in the West and East: autonomic responses and evaluative ratings. PLoS One, 8(3), e59312. https:/doi. org/10.1371/journal.pone.0059312.

Allen, J., Gregory, A., Mikami, A., Lun, J., Hamre, B., \& Pianta, R. (2013). Observations of effective teacherstudent interactions in secondary school classrooms: predicting student achievement with the classroom assessment scoring system-secondary. School Psychology Review, 42(1), 76-98.

Andersen, J. F., Andersen, P. A., \& Jensen, A. D. (1979). The measurement of nonverbal immediacy. Journal of Applied Communication Research, 7(2), 153-180. https://doi.org/10.1080/00909887909365204.

Arsenijevic, J., Andevski, M., \& Jockov, M. (2017). Role of communication in classroom management. The Anthropologist, 28(1-2), 69-78. https://doi.org/10.1080/09720073.2017.1316613.

Böckler, A., van der Wel, R. P., \& Welsh, T. N. (2014). Catching eyes: Effects of social and nonsocial cues on attention capture. Psychological Science, 25(3), 720-727. https://doi.org/10.1177/0956797613516147. 
Bolkan, S., Goodboy, A. K., \& Myers, S. A. (2017). Conditional processes of effective instructor communication and increases in students' cognitive learning. Communication Education, 66(2), 129-147. https://doi. org/10.1080/03634523.2016.1241889.

Brey, E., \& Shutts, K. (2015). Children use nonverbal cues to make inferences about social power. Child Development, 86(1), 276-286. https://doi.org/10.1111/cdev.12334.

Chen, J. (2016). Understanding teacher emotions: the development of a teacher emotion inventory. Teaching and Teacher Education, 55, 68-77. https://doi.org/10.1016/j.tate.2016.01.001.

Claessens, L. C. A., Van Tartwijk, J., Van der Want, A. C., Pennings, H. J. M., Verloop, N., Den Brok, P. J., \& Wubbels, T. (2017). Positive teacher-student relationships go beyond the classroom, problematic ones stay inside. The Journal of Educational Research, 110(5), 478-493. https://doi.org/10.1080 /00220671.2015.1129595.

ELAN (Version 5.2) [Computer software]. (2018). Nijmegen: Max Planck Institute for Psycholinguistics. Retrieved from https://tla.mpi.nl/tools/tla-tools/elan/

Ellis, K. (2000). Perceived teacher confirmation: the development and validation of an instrument and two studies of the relationship to cognitive and affective learning. Human Communication Research, 26(2), 264 291. https://doi.org/10.1111/j.1468-2958.2000.tb00758.x.

Gurtman, M. B. (2009). Exploring personality with the interpersonal circumplex. Social and Personality Psychology Compass, 3(4), 601-619. https://doi.org/10.1111/j.1751-9004.2009.00172.x.

Haataja, E., Garcia Moreno-Esteva, E., Salonen, V., Laine, A., Toivanen, M., \& Hannula, M.S. (2019a). Teacher's visual attention when scaffolding collaborative mathematical problem solving. Teaching and Teacher Education, 86. https://doi.org/10.1016/j.tate.2019.102877.

Haataja, E., Toivanen, M., Laine, A., \& Hannula, M. (2019b). Teacher-student eye contact during scaffolding collaborative mathematical problem-solving. LUMAT: International Journal on Math, Science and Technology Education, 7(2), 9-26. https://doi.org/10.31129/LUMAT.7.2.350.

Heikonen, L., Pietarinen, J., Pyhältö, K., Toom, A., \& Soini, T. (2017). Early career teachers' sense of professional agency in the classroom: associations with turnover intentions and perceived inadequacy in teacher-student interaction. Asia-Pacific Journal of Teacher Education, 45(3), 250-266. https://doi. org/10.1080/1359866X.2016.1169505.

Holmqvist, K., Nyström, M., Andersson, R., Dewhurst, R., Jarodzka, H., \& Van de Weijer, J. (2011). Eye tracking: a comprehensive guide to methods and measures. Oxford: Oxford University Press.

Kiesler, D. J. (1983). The 1982 interpersonal circle: a taxonomy for complementarity in human transactions. Psychological Review, 90(3), 185-214.

Kiesler, D. J. (1996). Contemporary interpersonal theory and research: personality, psychopathology, and psychotherapy. New York: Wiley.

Korthagen, F., Attema-Noordewier, S., \& Zwart, R. (2014). Teacher-student contact: exploring a basic but complicated concept. Teaching and Teacher Education, 40, 22-32. https://doi.org/10.1016/j. tate.2014.01.006.

Lausberg, H., \& Sloetjes, H. (2009). Coding gestural behavior with the NEUROGES-ELAN system. Behavior Research Methods, Instruments, \& Computers, 41(3), 841-849. https://doi.org/10.3758/BRM.41.3.591.

Lizdek, I., Sadler, P., Woody, E., Ethier, N., \& Malet, G. (2012). Capturing the stream of behavior: a computerjoystick method for coding interpersonal behavior continuously over time. Social Science Computer Review, 30(4), 513-521. https://doi.org/10.1177/0894439312436487.

McCluskey, R., Dwyer, J., \& Sherrod, S. (2017). Teacher immediacy and learning mathematics: effects on students with divergent mathematical aptitudes. Investigations in Mathematics Learning, 9(4), 157-170. https://doi.org/10.1080/19477503.2016.1245047.

McIntyre, N. A. (2016). Teach at first sight: expert teacher gaze across two cultural settings (doctoral dissertation). York: University of York.

McIntyre, N. A., \& Foulsham, T. (2018). Scanpath analysis of expertise and culture in teacher gaze in real-world classrooms. Instructional Science, 46(3), 435-455. https://doi.org/10.1007/s11251-017-9445-x.

McIntyre, N. A., Mainhard, M. T., \& Klassen, R. M. (2017). Are you looking to teach? Cultural, temporal and dynamic insights into expert teacher gaze. Learning and Instruction, 49, 41-53. https://doi.org/10.1016/j. learninstruc.2016.12.005.

Mehrabian, A. (1972). Nonverbal communication. Chicago: Aldine.

Mottet, T. P., Garza, R., Beebe, S. A., Houser, M. L., Jurrells, S., \& Furler, L. (2008). Instructional communication predictors of ninth-grade students' affective learning in math and science. Communication Education, 57(3), 333-355. https://doi.org/10.1080/03634520801989950.

Mottet, T. P., Beebe, S. A., \& Fleuriet, C. A. (2016). Students' influence messages. In T. P. Mottet, J. C. McCroskey, \& V. P. Richmond (Eds.), Handbook of instructional communication: rhetorical and relational perspectives (pp. 143-166). Abingdon: Routledge. 
Pennings, H. J. M., van Tartwijk, J., Wubbels, T., Claessens, L. C. A., van der Want, A. C., \& Brekelmans, M. (2014). Real-time teacher-student interactions: a dynamic systems approach. Teaching and Teacher Education, 37, 183-193. https://doi.org/10.1016/j.tate.2013.07.016.

Pennings, H. J. M., Brekelmans, M., Sadler, P., Claessens, L. C. A., van der Want, A. C., \& van Tartwijk, J. (2018). Interpersonal adaptation in teacher-student interaction. Learning and Instruction, 55, 41-57. https://doi.org/10.1016/j.learninstruc.2017.09.005.

Roberts, A., \& Friedman, D. (2013). The impact of teacher immediacy on student participation: an objective cross-disciplinary examination. International Journal of Teaching and Learning in Higher Education, 25(1), $38-46$.

Sadler, P., Ethier, N., Gunn, G., Duong, D., \& Woody, E. (2009). Are we on the same wavelength? Interpersonal complementarity as shared cyclical patterns during interactions. Journal of Personality and Social Psychology, 97(6), 1005-1020. https://doi.org/10.1037/a0016232.

Schmitz, B. (2006). Advantages of studying processes in educational research. Learning and Instruction, 16(5), 433-449. https://doi.org/10.1016/j.learninstruc.2006.09.004.

Tatler, B., \& Land, M. (2015). Everyday visual attention. In J. Fawsett, E. Risko, \& A. Kingstone (Eds.), The handbook of attention (pp. 391-421). Cambridge: MIT Press.

Thomas, K. M., Hopwood, C. J., Woody, E., Ethier, N., \& Sadler, P. (2014). Momentary assessment of interpersonal process in psychotherapy. Journal of Counseling Psychology, 61(1), 1-14.

Toivanen, M., Lukander, K., \& Puolamäki, K. (2017). Probabilistic approach to robust wearable gaze tracking. Journal of Eye Movement Research, 10(4), 1-26. https://doi.org/10.16910/jemr.10.4.2.

Wiggins, J.S. (1991). Agency and Communion as conceptual coordinates for the understanding and measurement of interpersonal behavior. In W.M. Grove, D. Cicchetti (Eds.), Thinking clearly about psychology(vol 2, pp. 89-113). Minneapolis, MN: Personality and psychopathology, University of Minnesota Press.

Zeki, C. P. (2009). The importance of non-verbal communication in classroom management. Procedia - Social and Behavioral Sciences, 1(1), 1443-1449. https://doi.org/10.1016/j.sbspro.2009.01.254.

Publisher's Note Springer Nature remains neutral with regard to jurisdictional claims in published maps and institutional affiliations.

\section{Affiliations}

\section{Eeva Haataja $^{1} \cdot$ Visajaani Salonen $^{1} \cdot$ Anu Laine $^{1} \cdot$ Miika Toivanen $^{1} \cdot$ Markku S. Hannula ${ }^{1}$}

Visajaani Salonen

visajaani.salonen@helsinki.fi

Anu Laine

anu.laine@helsinki.fi

Miika Toivanen

miika@seetruetechnologies.com

Markku S. Hannula

markku.hannula@helsinki.fi

1 Faculty of Educational Sciences, University of Helsinki, P.O. Box 9, FI-00014 Helsinki, Finland 